\title{
Parent personal information system to improve parental involvement in children's learning process in elementary school
}

\begin{abstract}
Parent plays a vital role in children's learning development process particularly with an active involvement encourage the children higher academic achievement in school. However, parental involvement with their child's teachers and administrator in elementary school in Malaysia is still fairly low. Inadequate parental participation in school is due to lacking of information given to the parents and ineffective traditional means when information dissemination carries out through the children. This study intends to helps school to enhance parental engagement, by communicating with parent regularly, conveniently and through a method usable by the parent. Therefore to improve the communication problems between parents and school an efficient and effective communication system that allows parent to be informed and involved is necessary. This paper focuses on two parts: to identify the system requirements using the Problem PyramidÊ and to design a better personal information management using mobile platform for supporting parental engagement.
\end{abstract}

Keyword: Parental involvement; Experience design; Personal information management; Mobile technology; Qualitative approach 